\title{
EFFECT OF CRUDE EXTRACT AND PHYTOSTEROL FRACTION OF FUMARIA OFFICINALIS IN INDUCED HYPERTROPHIC SCAR OF RABBITS
}

\author{
HANAN S NOORI ${ }^{1 *}$, AHMED ABU-RAGHIF ${ }^{2}$
}

Department of Pharmacology and Therapeutics, College of Medicine, AL-Nahrain University, Iraq. Email: hanan11sabah@gmail.com

Received: 25 October 2018, Revised and Accepted: 02 January 2019

\section{ABSTRACT}

Objective: The present study aimed to evaluate the role of crude extract and phytosterol fraction of Fumaria officinalis in experimentally induced hypertrophic scar in rabbits.

Methods: Surgical wounds were performed on day 1 with an 8-mm biopsy punch four wounds were created on the ventral surface of the rabbit ear (in vivo) down to cartilage. Triamcinolone acetonide (TAC), crude and phytosterol extracts of $F$. officinalis L. are administered topically to established scars on day 31 . The outcome measures included study of histopathology of skin sections, transforming growth factor beta-1 (TGF- $\beta 1$ ), level, and collagen three alpha1 in skin tissue.

Results: In comparison with the induced hypertrophic scar, all treatment produced a significant reduction in scores of TGF $\beta 1$, collagen III, inflammation, and measurement of SEI ( $\leq \leq 0.01)$. The most significant reduction in inflammation and thickness observed in TAC and extract of crude F. officinalis L. Only crude F. officinalis L. decrease fibroblast counts in comparison to induced hypertrophic scar group and other group (p $\leq 0.05$ ). No statistically significant differences were found between the treatment groups in terms of TGF $\beta 1$ and collagen III.

Conclusion: Topical crude extract of F. officinalis L. was more effective in the treatment of induced hypertrophic scar as compared with phytosterol of F. officinalis L. and comparable to the effectiveness of topical TAC.

Keywords: Hypertrophic scar, Rabbit ear model, SEI, Collagen I.

(C) 2019 The Authors. Published by Innovare Academic Sciences Pvt Ltd. This is an open access article under the CC BY license (http://creativecommons. org/licenses/by/4. 0/) DOI: http://dx.doi.org/10.22159/ajpcr. 2019.v12i2.30448

\section{INTRODUCTION}

Hypertrophic scars are fibroproliferative disorders that result from abnormal wound healing, defined as increased or decreased regulation of specific wound healing processes [1]. It is raised, red, rigid, and responsible for severe functional and cosmetic problems, primarily contain collagen type III orientated parallel to the epidermal surface with abundant collagen nodules [2]. Furthermore, nodular structures in which alpha-smooth muscle actin - expressing myofibroblasts, small vessels, are present characterize hypertrophic scars [3]. Pathological scarring is a significant post-operative complication that is difficult to predict and prevent [4]. Each year in the developed world, approximately 100 million people suffer from scar-related tissues [5]. The incidence of hypertrophic scarring has varied in studies between $32 \%$ and $67 \%$ rises to $75 \%$ in children, young adults and those with pigmented skin [6] and up to $91 \%$ following burn injury, depending on the depth of the wound [2]. The underlying mechanisms of scar formation are complicated, and the process may be affected by multiple factors [7]. The physiologic response to wounding in adult tissue is the formation of a scar, a process that can be temporally grouped into three distinct phases: Inflammation, proliferation, and remodeling [8]. Within these stages, which often overlap, there are numerous interactions between fibrotic and anti-fibrotic growth factors, cells, extracellular matrix (ECM) components, and various enzymes [9]. To date, a number of signaling pathways have been implicated in the pathogenesis of hypertrophic scar; TGF- $\beta$ is a family of growth factors considered to be the master regulator of fibrosis and its effects on collagen deposition, cell proliferation, immune modulation, apoptosis, differentiation, and several other processes have been well established in hypertrophic scar [10]. The three isoforms of TGF- $\beta$ (TGF- $\beta 1,-\beta 2$, and $-\beta 3$ ) are secreted as inactive latent precursors that require activation before binding to the TGF- $\beta$ receptors [11]. There appears to be an alteration in TGF- $\beta$ signaling (through increased phosphorylation of the receptor
SMAD proteins) in hypertrophic-derived fibroblasts and a decreased expression of the inhibitory SMAD 7 in hypertrophic scar-derived fibroblasts [12]. The majority of cells involved in wound healing express TGF- $\beta$ in an inactive form that actively promotes the chemotaxis of fibroblasts to the site of injury [3]. Fibroblasts derived from hypertrophic scars have demonstrated both an increased expression of the pro-fibrotic cytokine, transforming growth factor beta 1 (TGF- $\beta 1$ ), and prolonged feeling of the associated TGF- $\beta$ receptors [13]. This study aimed to investigate our hypothesis that crude extract and phytosterol fraction of Fumaria officinalis may be successful in the therapeutic modulation of scar formation in vivo.

The genus Fumaria L. (Fumariaceae) consists of 60 species widely distributed all over the world [14]. F. officinalis $L$. is an annual herbaceous plant, the medicinal parts are represented by the dried aerial parts harvested during flowering [15]. This herb is a component of several phytopharmaceuticals, mainly used to treat functional diseases of the hepatobiliary system discernible as colicky pains affecting the gallbladder, biliary system, and gastrointestinal tract [16]. Fumaria also used to treat chronic eczema, cutaneous eruptions, and other dermatological circumstances [17]. The fumaric acid esters have used as an action for psoriasis for nearly 30 years [18]. Studies showed significant antioxidant activity in vitro; nevertheless, that is not known whether it is equally effective in vivo [19]. This management is giving us interesting to apply this compound in the current study. On the other hand, phytosterol is a large group of compounds that are found exclusively in plants. They are structurally related to cholesterol and have cholesterol reduction effect and prevention against certain types of cancer such as colon, breast, and prostate [20], and also stimulation of immunity and protection of skin [21].

\section{METHODS}

A total of 48 healthy male albino rabbits between 6 and 12 months of age were used in the study. Before starting the work, the animals were 
left for $48 \mathrm{~h}$ to acclimatize to the animal room conditions of controlled temperature $\left(28-30^{\circ} \mathrm{C}\right)$, allowed free access to water ad libitum and food. Protocol of the current research was approved by the Institute Review Board Al-Nahrain University College of Medicine. Rabbits described hypertrophic scar model were anesthetized with (IM) injection of ketamine $(45 \mathrm{mg} / \mathrm{kg}$ ) and xylazine $(5 \mathrm{mg} / \mathrm{kg})$. Surgical wounds were performed on day 1 with an 8-mm biopsy punch. Four injuries were created meticulously on the ventral surface of one ear down to cartilage. Removal of the perichondrial layer delayed epithelization after the hemostasis has been achieved with manual pressure; wounds were covered with sterile gauze for 1 day. On day 30, and the eventual scars were obtained.

\section{Plant material}

The herb included in this study was identified and authenticated in the Pharmacognosy Department, College of Pharmacy, University of Baghdad, Iraq

\section{Preparation of extracts}

Powder from aerial parts of $F$. officinalis $(250 \mathrm{mg}$ ) was extracted with $90 \%$ ethanol $(600 \mathrm{ml})$ in reflex apparatus until complete exhaustion and evaporation to give crude fraction. Crude extract was acidified with hydrochloric acid (5\%) at $\mathrm{pH} 2$ then partitioned with equal volume of ethyl acetate to give two layers (aqueous and ethyl acetate) layer, ethyl acetate layer was collect, evaporated then basified with $300 \mathrm{ml}$ of sodium hydroxide $5 \%$, and extracted with chloroform to get also two layers, two types of solvent: methanol $80 \%$ and petroleum ether was added to chloroform layer to obtain phytosterol in petroleum ether fraction [22].

\section{High-performance liquid chromatography (HPLC) analysis}

The sterol compound of $F$. officinalis was determined by a Waters Germany HPLC system with ODS column (250 $\mathrm{mm} \times 4.6 \mathrm{~mm}, 5 \mu \mathrm{m})$. $1 \mathrm{mg}$ of sterol fraction was dissolved in $5 \mathrm{ml} 70 \%$ methanol and detected at $210 \mathrm{~nm}$ at a flow rate of $1 \mathrm{ml} / \mathrm{min}$. The data were analyzed with the phytosterol standards prepared as a solution of three standard concentrations of each $0.5 \mathrm{mg} / 1 \mathrm{ml}$ of standards in methanol and performed as a single run in HPLC [23].

\section{Preparation of gels formulations}

The concentration of chemical (s) and extract (s) was weighed and dissolved in $10 \mathrm{ml}$ of absolute ethanol alcohol to prepare (solution A) after that $3 \mathrm{~g}$ powder of HPMC was added to the $75 \mathrm{ml}$ of distilled water with stirring to get (solution B). Solutions A and B were mixed thoroughly, and the final weight was made up to $100 \mathrm{~g}$ [24]. All the samples were allowed to equilibrate for at least $24 \mathrm{~h}$ at room temperature [25].

\section{Treatment groups}

The treatment groups are as follows: Group 1 - Healthy animal group; Group 2 - hypertrophic scar was induced, and the animals left without treatment (only base gel); Group III - rabbits with induced hypertrophic scar treated with triamcinolone acetonide (TAC) $0.1 \%$ as standard drug; Group VI - rabbits with induced hypertrophic scar treated topically with crude extract of F. Officinalis L.3\%; and Groups V, VI - rabbits with induced hypertrophic scar treated with phytosterol extract of F. officinalis L. $0.2 \%$ and $0.4 \%$, respectively. Dugs and extracts were given twice daily for 21 days as formulated topical gel.

\section{Collection of samples}

The samples were collected from each animal after anesthetized the animals at the end of the experiment (51 days) using $11 \mathrm{~mm}$ bunch biopsy with more than $3 \mathrm{~mm}$ margin of adjacent skin [26] then submitted for histological and immunohistochemical analysis.

\section{Preparation of the samples}

Each wound sample was stored in $10 \%$ formaldehyde solution prepared in section to use for histopathological and immunohistochemistry study.

\section{Preparation of formalin-fixed paraffin-embedded tissues}

Tissue fixation sections transferred into formalin (10\%); fixative volume was 20 times that of tissue on a weight per volume, tissue was fixed for a minimum $48 \mathrm{~h}$ at room temperature and then processed, using gentle agitation [27], then tissues embedded in paraffin blocks.

\section{Tissue sectioning and slide preparation}

Serial sections (3-5 $\mu \mathrm{m})$ thickness were obtained using microtome, from each wound paraffin block, 105 slides were prepared. Sections were mounted on ordinary slides (to be used in Hematoxylin and Eosin [H\&E] staining system) and on positively charged slides (to be used for immunohistochemistry) using a water bath of $45^{\circ} \mathrm{C}$ to prevent tissues sections folding during mounting procedure, each slide was labeled using a pencil to carry the same number on its paraffin block.

\section{H\&E staining of paraffin sections}

The Haematoxylin and Eosin staining system were used for histopathological examination as desceibed by Anderson et al., (1996) [29].

\section{Assessment of histopathological changes in skin sections}

SEI index is the ratio of the highest vertical height of scar area between perichondrium and skin surface to the highest vertical height of normal area around the scar between perichondrium and skin surface. Each wound was measured by a blinded examiner using a calibrated eyepiece reticule [29].

The degree of inflammation and fibroblast counts was evaluated in a semi-quantitative manner. The degree of inflammation was evaluated according to the following scores: $0=$ none; 1 = mild; 2 = moderate; and 3 = severe. Fibroblast count was evaluated according to the following scores: $0=$ absence of fibroblasts; 1 = few fibroblasts; 2 = presence of disorganized fibroblasts; and 3 = presence of fibroblasts parallel to the wound surface [30].

Immunohistochemistry IHC detection of collagen III, TGF $\beta 1$

(I) Anti-collagen III antibody: Rabbit polyclonal antibody to collagen III (Code number: MBS822102) (MyBioSource, USA). (II) Anti-TGF $\beta 1$ antibody: Rabbit polyclonal antibody to TGF $\beta 1$ (Code number: ab190503) (Abcam, UK).

\section{Immunohistochemistry IHC procedure:}

Five $\mu \mathrm{m}$ thick sections were made on positively charged slides, and the staining procedure was perform as in manufacture protocol, using ab80436 staining kit. Immunohistochemistry kits for detection of collagen 3 alpha1, TGF- $\beta 1$.

\section{EVALUATION OF IHC RESULTS}

Quantification of TGF- $\beta 1$ and collagen protein expression was evaluated under light microscopy at X20. The extent of the immunohistochemical reaction of ECM proteins, such as collagen, was measured by ranking the signal intensities according to the following scale: - (absent), + (mild), ++ (moderate), and +++ (marked) [31]. Stained slides were examined to identify immunoreactivity for TGF- $\beta 1$. Scoring system was done, and the score recorded was the average intensity of the expression: Absence of immunoreactivity had score 0 , weak immunoreactivity had score1, moderate immunoreactivity had score 2; and strong immunoreactivity had score 3 [32].

\section{Statistical analysis}

Data were collected, summarized, analyzed, and presented using two statistical software programs: The statistical package for the social sciences (SPSS version 22) and Microsoft Office Excel 2013. All results are presented as means \pm SD. Comparison of mean values between the two groups was carried out using the Mann-Whitney U-test and unpaired t-test. Data for multiple comparisons were performed by Kruskal-Wallis test, post hoc Tukey test, and one-way ANOVA. $P \leq 0.05$ was considered significant and highly significant when $P \leq 0.01$ [33].

\section{RESULTS}

\section{Healing rate}

Appearance of untreated induced hypertrophic scar

Normal healing process involves three overlapping phases: Inflammation (0-3 days), cellular proliferation (3-12 days), and 
remodeling (3-6 months), so in this group there is inflammatory signs seen from the $1^{\text {st }}$ day in all animals with partial wound closure starting from the $4^{\text {th }}$ day and excessive formation of fibrosis (100\% induction) at $30^{\text {th }}$ day as shown in Figure 1.

Group III (induced hypertrophic scar in rabbits treated with triamcinolone acetonide): Healing signs were very clear starting after treatment with fading of the inflammatory sign. Finally, complete wound closure and decrease thickness of scar (after 21 days of treatment) Figure 2a.

Group IV (induced hypertrophic scar in rabbits treated with crude F. officinalis) Figure 2b: Remarkable decrease of inflammatory signs occurred after starting treatment with the closure of the wound and no sign of thickness after 21 days of treatment.

Group V (induced hypertrophic scar in rabbits treated with $0.2 \%$ phytosterol fraction of $F$. officinalis): This group showed a gradual

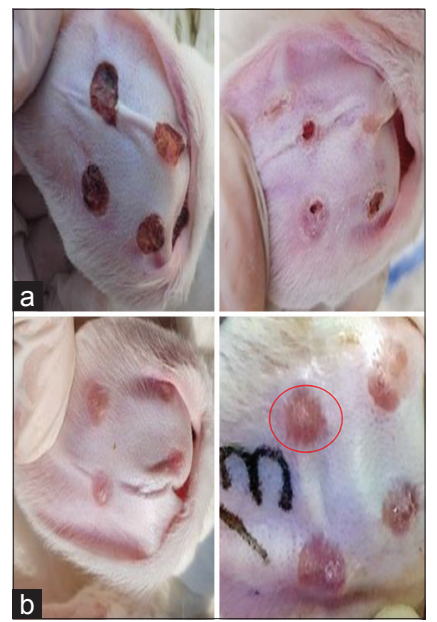

Figure 1: ( $a$ and b) Gross morphological features of healing rate in the induced hypertrophic scar of rabbits during 30 days decrease of the inflammatory sign with the close of the wound and a moderate reduction of thickness after 21 days of treatment Figure 2c.

Group VI (induced hypertrophic scar in rabbits treated with $0.4 \%$ phytosterol fraction of $F$. officinalis): Healing signs were very clear starting after treatment with fading of the inflammatory sign. Finally, complete wound closure and decrease thickness of scar after 21 days of treatment Figure 2d.

\section{IMMUNOHISTOCHEMICAL RESULTS}

Immunohistochemical for TGF- $\beta 1$ and collagen III is shown in Table 1 , Figures 3 and 4 . There was an extremely high significant difference in mean of immunohistochemical scores of TGF- $\beta$ and collagen III between healthy control and induced hypertrophic scar group enrolled in the present study $(\mathrm{p} \leq 0.001)$.

All treatment groups showed a highly significant reduction in IHC expression scores of TGF- $\beta$ and collagen III ( $p \leq 0.01$ ) as compared to induced hypertrophic scar. No significant variation in TGF- $\beta 1$ and collagen III marker was observed between groups ( $p>0.05)$ as shown in Table 2 and Figure 5.

\section{Histological results}

Histopathological score reflective of scar in experimentally induced hypertrophic scar was shown to be extremely high significant ( $\mathrm{p} \leq 0.001$ ) increased in the induced hypertrophic group without treatment in comparsion to the healthy control group as show in Table 3 and Figure 6. All treatment groups produced a significant reduction in inflammatory in comparison with induced hypertrophic scar group ( $\mathrm{p} \leq 0.001)$. Highly significant reduction was observed in scar elevation index of TAC, extract of $F$. officinalis L. and both concentration of $0.4 \%$ and $0.2 \%$ of phytosterol extract of $F$. officinalis L., respectively, as compared with induced hypertrophic scar $(\mathrm{p} \leq 0.01)$. The only crude extract of $F$. officinalis L. produced a significant reduction of fibroblast count in comparison to induced hypertrophic scar group and another group $(\mathrm{p}=0.002)$. Both TAC and crude extract of $F$ officinalis $\mathrm{L}$. produced the most significant reduction in inflammation and thickness of hypertrophic scar as compared to other treatment groups. All results are shown in Tables 3 and 4, Figures 6-9.
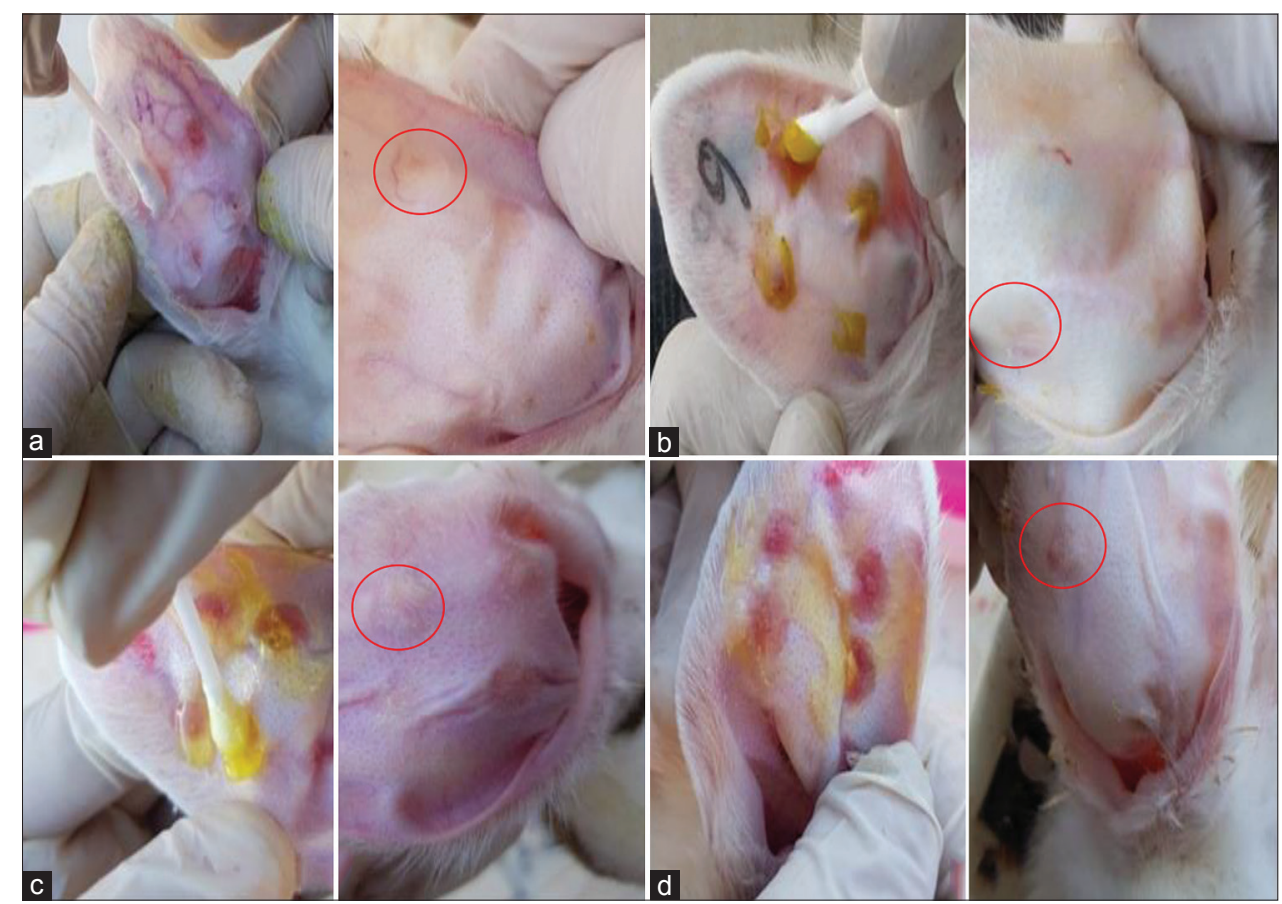

Figure 2: The application and effect of treatment groups after 21 days (a) Triamcinolone acetonide, (b) Crude Fumaria officinalis, (c) $0.4 \%$ phytosterol, (d) $0.2 \%$ phytosterol 
Table 1: Mean of TGF- $\beta 1$ and collagen III in the control and study groups

\begin{tabular}{|c|c|c|c|c|c|c|}
\hline Parameters & G1 $n=8$ & G2 $n=8$ & G3 $n=8$ & G4 $n=8$ & G5 $n=8$ & G6 $n=8$ \\
\hline \multicolumn{7}{|l|}{ TGF- $\beta 1$} \\
\hline Mean \pm SD & $1.13 \pm 0.35$ & $3.0 \pm 0.0$ & $2.0 \pm 0.54$ & $1.38 \pm 0.74$ & $1.5 \pm 0.54$ & $1.75 \pm 0.46$ \\
\hline $\mathrm{p}$ value & $<0.001$ & & $0.002^{*}$ & $0.002 *$ & $<0.001^{*}$ & $<0.001^{*}$ \\
\hline \multicolumn{7}{|l|}{ Collagen III } \\
\hline Mean \pm SD & $1.0 \pm 0.0$ & $3.0 \pm 0.0$ & $2.13 \pm 0.64$ & $1.5 \pm 0.76$ & $1.5 \pm 0.54$ & $1.63 \pm 0.52$ \\
\hline $\mathrm{p}$ value & $<0.001$ & & $0.010^{*}$ & $0.002^{*}$ & $<0.001^{*}$ & $<0.001^{*}$ \\
\hline
\end{tabular}

Mann-Whitney U-test. SD standard deviation; $\mathrm{p}$ indicates the level of significance at $\mathrm{p} \leq 0.05$; ${ }^{*}$ Indicate a comparison between induced hypertrophic scar and another group. (G1) Healthy control, (G2) Induced hypertrophic scar, (G3) TA steroid, (G4) crude FO, (G5) phytosterol 0.2\%, (G6) phytosterol 0.4\%. TGF- $\beta 1$ : Transforming growth factor-beta 1

Table 2: Immunohistochemical comparison between study groups in TGF $\beta 1$ COLIII $\alpha$ I

\begin{tabular}{llllll}
\hline Parameters & G3 $\mathbf{n = 8}$ & G4 n=8 & G5 n=8 & G6 n=8 & p value \\
\hline $\begin{array}{c}\text { TGF } \beta 1 \\
\text { Mean } \pm \text { SD }\end{array}$ & $2.0 \pm 0.54$ & $1.38 \pm 0.74$ & $1.5 \pm 0.54$ & $1.75 \pm 0.46$ & 0.157 \\
$\begin{array}{c}\text { COLIII } \\
\text { Mean } \pm \text { SD }\end{array}$ & $2.13 \pm 0.64$ & $1.5 \pm 0.76$ & $1.5 \pm 0.54$ & $1.63 \pm 0.52$ & 0.132 \\
\hline
\end{tabular}

Kruskal-Wallis test SD: Standard deviation; $p$ indicates the level of significance at $\mathrm{p} \leq 0.05 ; \mathrm{n}$ : Number of animals, G3 TA steroid, G4 crude FO, G5 phytosterol $0.2 \%$ and G6 phytoserol 0.4. (G1) healthy control, (G2) Induced hypertrophic scar, (G3) TA steroid, (G4) crude F0, (G5) phytosterol $0.2 \%$, (G6) phytosterol $0.4 \%$. COLIII $\alpha$ I: Collagen 3 alpha1

HPLC

Retention time of three sterols fraction was shown in Table 5 and Figure 10 . Scanning profile of $90 \%$ hydroalcoholic extract of phytosterol fraction of $f$. officinalis L.in HPLC method showed $\beta$-sitosterol at RT 4.9, stigmasterol at RT 5.3 and campesterol at RT at 2.7.

\section{DISCUSSION}

Hypertrophic scars are a complex pathologic process which characterized by proliferation of the dermal tissue, excessive deposition of fibroblast-derived ECM over a prolonged period and persistent inflammation and fibrosis [34]. Such pathological scarring can lead to severe functional impairment, psychological morbidity, and costly long term health care [35]. The treatment for HS remains a difficult problem to prevent and treat [36], which is embodied in several aspects as follows: (1) The treatment time is too long, (2) lack of specific remedies, various management must join to apply, which are still not so much useful for the scar disease, (3) several drugs have side effects, leading to the limit of dosage and cure time, and (4) the lack of early interventions may deprive the optimal time for treating [37] for this reasons hypertrophic scar make a strong stimulus to find out a new relatively safe and effective modality of treatment which may serve as the early intervention to treat HS more effectively or intensify the function of corticosteroids and chemotherapeutic agents. The rabbit dermal model was used and validated in a variety of studies evaluating the effect of age on scars, molecular mechanisms agents, and efficacy of therapeutics [38].

TGF- $\beta$ can mediate fibroblast proliferation, angiogenesis, ECM synthesis, and re-epithelialization in the wound-healing process [39]. On the other hand, it was demonstrated that fibrogenic response to injury is mediated through angiotensin II induction of TGF- $\beta 1$ expression [40]. Particularly, TGF- $\beta 1$ transcriptionally regulates various fibrosis-related proteins, including Type I and III collagens [41]. It can also promote the transformation of fibroblasts to myofibroblasts, which are the significant cells contributing to HS formation and characterized by an increased synthesize collagen and up regulation of cytokines [42]. In the current study, the rabbit ear hypertrophic scar model was successful as there were significant differences between induced hypertrophic scar and healthy skin in cellular response to growth factors (TGF- $\beta$ ) which is consistent with the finding of Kim et al. 2015 [43].

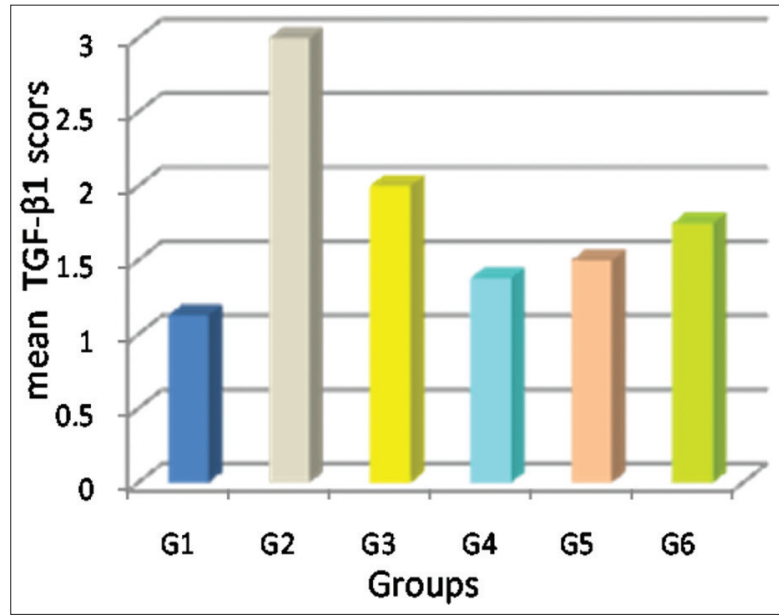

Figure 3: Mean transforming growth factor-beta 1 (TGF- $\beta 1$ ) scores in the control and study groups. (G1) Healthy control,(G2) induced hypertrophic scar, (G3) TA steroid, (G4) crude FO, (G5) phytosterol $0.2 \%$, (G6) phytosterol $0.4 \%$

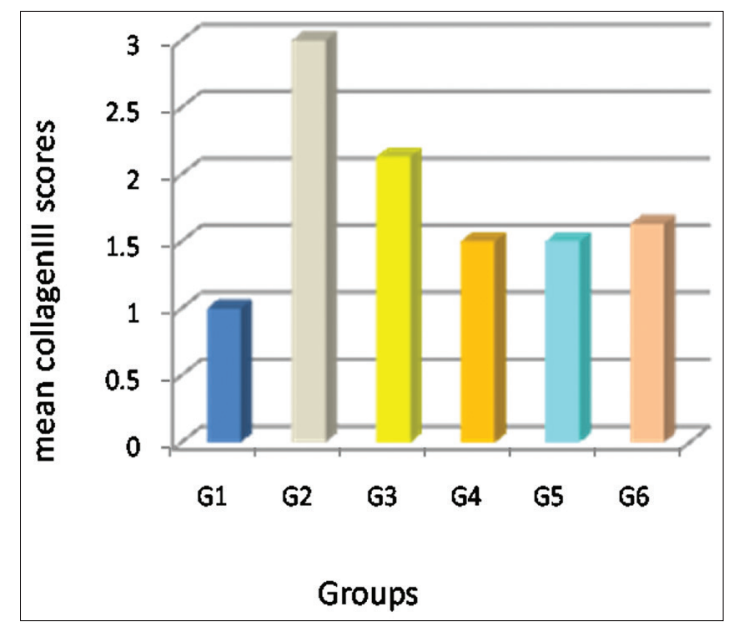

Figure 4: Mean collagen III scores in the control and study groups. (G1) healthy control, (G2) induced hypertrophic scar, (G3) triamcinolone acetonide steroid, (G4) crude FO, (G5) phytoserol $0.2 \%$, (G6) phytoserol $0.4 \%$

Topical TAC in this study caused significant reduction of TGF- $\beta 1$ as compared to induced scar non-treated group after 21 days of treatment $(\mathrm{p} \leq 0.05)$ that is in accordance with Sari et al.[44] which found significant differences of pro-inflammatory cytokines TGF- $\beta 1$ and collagen III in rabbit ear model after treatment with topical TAC.

Regarding F. officinalis, there no previous reports on the effect of Fumaria on hypertrophic scar which refer to the novelty of the current study. Crude ethanolic extract prepared from aerial parts of the 


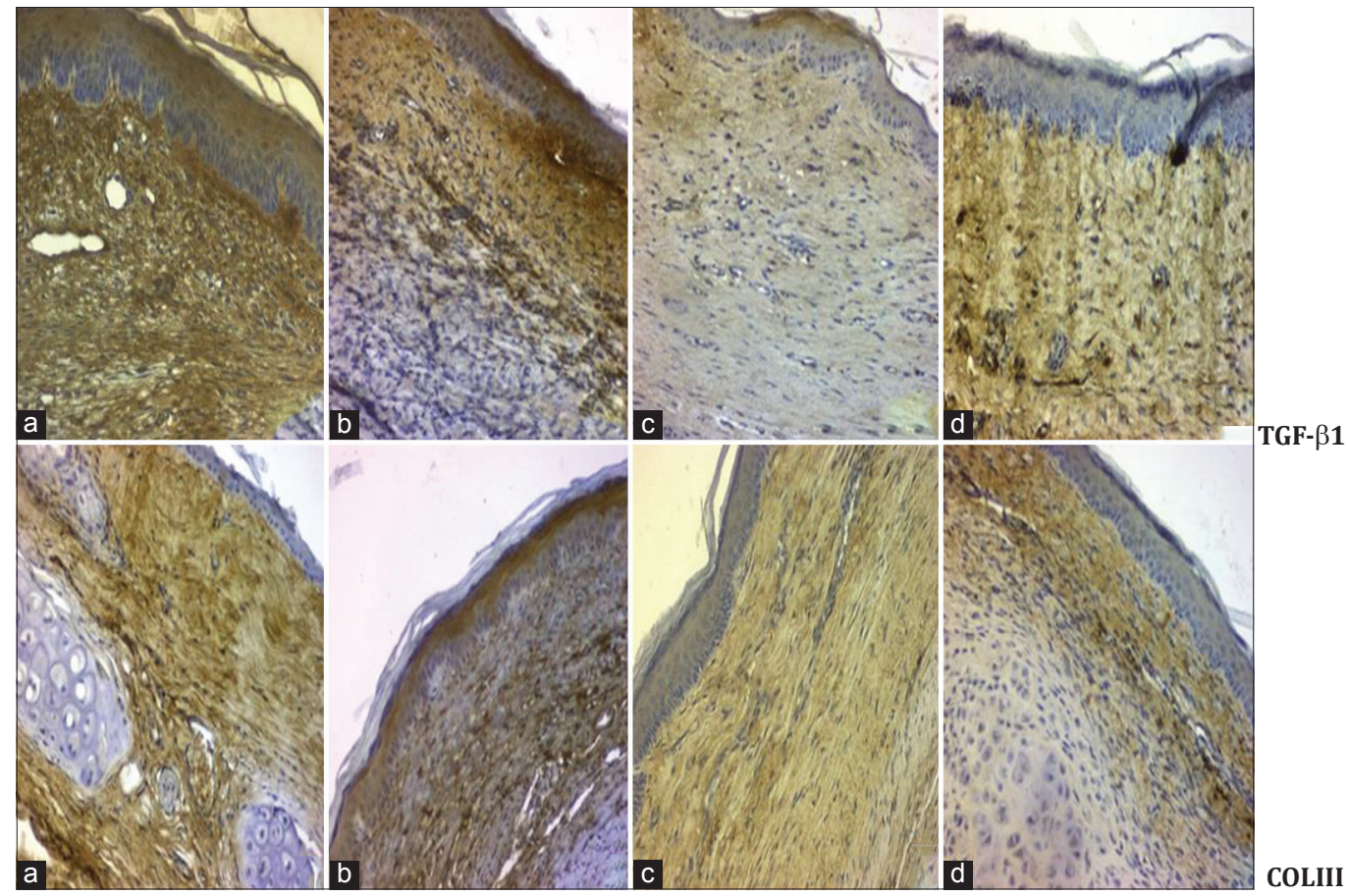

Figure 5: Cytoplasmic immunohistochemically expression of transforming growth factor-beta 1 (TGF- $\beta 1$ ) and extracellular immunohistochemically expression of collagen III of treatment groups $(\times 20)$. (a and b) Hypertrophic scar showed moderate intensity TGF- $\beta 1$ and collagen 3 (COLIII) in triamcinolone acetonide-treated group and $0.4 \%$ phytosterol treated group, respectively (c and d). Hypertrophic scar shown mild intensity TGF- $\beta 1$ and COLIII in FO treated group and $0.2 \%$ phytosterol treated group, respectively

Table 3: Mean of histological outcome in the control and study groups

\begin{tabular}{|c|c|c|c|c|c|c|}
\hline Parameters & G1 $n=8$ & G2 $n=8$ & G3 $n=8$ & G4 $n=8$ & G5 $n=8$ & G6 $n=8$ \\
\hline \multicolumn{7}{|c|}{ Fibroblast count } \\
\hline Mean \pm SD & $0.0 \pm 0.0$ & $2.0 \pm 0.0$ & $2.25 \pm 0.46$ & $2.88 \pm 0.35$ & $2.25 \pm 0.46$ & $2.5 \pm 0.54$ \\
\hline $\mathrm{p}$ value & $<0.001$ & & $0.442^{*}$ & $0.002^{*}$ & $0.442^{*}$ & $0.105^{*}$ \\
\hline \multicolumn{7}{|l|}{ Inflammation } \\
\hline Mean \pm SD & $0.0 \pm 0.0$ & $2.75 \pm 0.46$ & $0.75 \pm 0.46$ & $0.75 \pm 0.46$ & $1.88 \pm 0.35$ & $1.13 \pm 0.35$ \\
\hline $\mathrm{p}$ value & $<0.001$ & & $<0.001^{*}$ & $<0.001^{*}$ & $<0.001^{*}$ & $<0.001^{*}$ \\
\hline \multicolumn{7}{|c|}{ Scar elevation index } \\
\hline Mean \pm SD & $1.0 \pm 0.0$ & $8.03 \pm 0.87$ & $3.03 \pm 0.42$ & $3.94 \pm 1.11$ & $5.97 \pm 1.54$ & $4.4 \pm 1.59$ \\
\hline $\mathrm{p}$ value & $<0.001$ & & $<0.001^{*}$ & $<0.001^{*}$ & $0.005^{*}$ & $<0.001^{*}$ \\
\hline
\end{tabular}

Unpaired t-test, Mann-Whitney U-test. SD standard deviation; $\mathrm{p}$ indicates the level of significance at $\mathrm{p} \leq 0.05$; ${ }^{*}$ Indicate a comparison between induced hypertrophic scar and another group. (G1) healthy control, (G2) induced hypertrophic scar, (G3) TA steroid, (G4) crude F0, (G5) phytosterol 0.2\%, (G6) phytosterol 0.4\%

plant and phytosterol fraction caused significant reduction of TGF- $\beta$ with a slight difference in reduction of TGF- $\beta 1$ between two doses of phytosterol topical gel. Three phytosterols: $\beta$-sitosterol, campesterol was identified by HPLC method.

The result of the current study is in agreement with Jurjus et al.[45] that studied the effect of MEBO which is composed of beta-sitosterol $0.25 \%$ as an active ingredient in the induced burn of the rabbit.

Model and found persistent rise in levels of TGF- $\beta 1$ from day 2 to day 9 then dropping back on days 12 and 15. Furthermore, the reduction of TGF $\beta 1$ in crude F. officinalis L. may be due to Fumaric acid esters which were isolated for the $1^{\text {st }}$ time from the plant $F$. officinalis [46]. Ivanov et al. in[47] discussed chemical constituent in 5 fumaria species (Fumariaceae) and found the highest phenolic content such as quercetin, p-coumaric, and ferulic acids in the extract of $F$. oficinalis; this compound has antioxidant activity, anti-inflammatory, and anti-proliferative effects $[48,49]$. Triamcinolone acetonide, $F$. officinalis L. and its fraction of phytosterol in two doses were effective in reduction immunohistochemical marker of TGF- $\beta 1$, and no difference between them was observed. In terms of collagen III, the result of the current study proves the elevation of this biomarker in induced hypertrophic scar group, which is consistence with the finding of Oliveira et al. [50]. Research also showed significant reduction of collagen III in TAC group as compared to untreated induced scar after 21 days of treatment $(\mathrm{p} \leq 0.05)$ that is in agreement with the findings of Uzun et al. in 2013 [51].

Crude F. officinalis L. and both concentration of phytosterol extract $(0.2 \%$, $0.4 \%$ ) showed a significant decrease in collagen III with more reduction was observed in a lower dose of phytosterol topical gel; this finding is in accordance with Rizvi et al. [52] that demonstrated the significant effect of Fumaria parviflora leaves in reduce the number of fibroblasts, synthesis of collagen and mucopolysaccharide of cotton pellet-induced granuloma in rats after 7 days treatment. $F$. officinalis affect ECM structure of the dermis layer due to inhibition of pro-inflammatory cytokine $\mathrm{TNF} \alpha$, interleukin (IL)-6, and anti-inflammatory cytokine IL-1 that consider powerful chemotactic agents for macrophages and fibroblasts proliferation [53]. Triamcinolone acetonide, F officinalis L. and its fraction of phytosterol in two doses were effective in reduction immunohistochemical marker of collagen III and no difference between them was observed. Hypertrophic scar differs from the normal wound healing process in an inflammatory response with increasing cellular migration, proliferation, matrix deposition, and tissue remodeling. 
Table 4: Comparison of histological parameters between every pair of study groups

\begin{tabular}{llll}
\hline Dependent variable & $\mathbf{1}^{\text {st }}$ group & $\mathbf{2}^{\text {nd }}$ group & p value \\
\hline Fibroblast count & G4 & G3 & 0.038 \\
Inflammatory degree & G5 & G5 & \\
& & G3 & 0.001 \\
Scar elevation index & G5 & G6 & 0.010 \\
& & G3 & 0.016 \\
\hline
\end{tabular}

Kruskal-Wallis test post hoc Tukey test indicates the level of significance at $\mathrm{p} \leq 0.05$, (G3) TAC steroid, (G4), crude FO,(G5) phytosterol 0.2\%, (G6) phytosterol $0.4 \%$. TAC: Triamcinolone acetonide

Table 5: Retention time of phytosterol compounds

\begin{tabular}{ll}
\hline Standard & Retention time (min) \\
\hline B-sitosterol & 4.9 \\
stigmasterol & 5.3 \\
campesterol & 2.7 \\
\hline
\end{tabular}

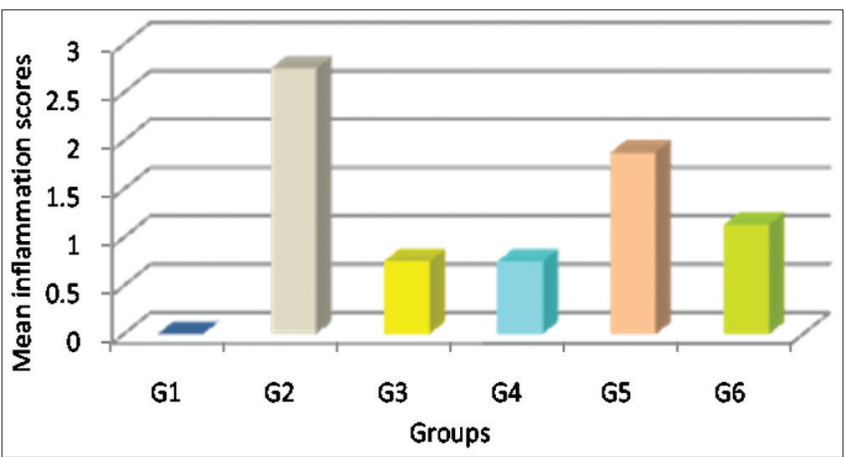

Figure 6: Mean of inflammation score in control and study groups (G1) healthy control, (G2) induced hypertrophic scar, (G3) triamcinolone acetonide steroid, (G4) crude FO, (G5) phytosterol $0.2 \%$, (G6) phytosterol $0.4 \%$

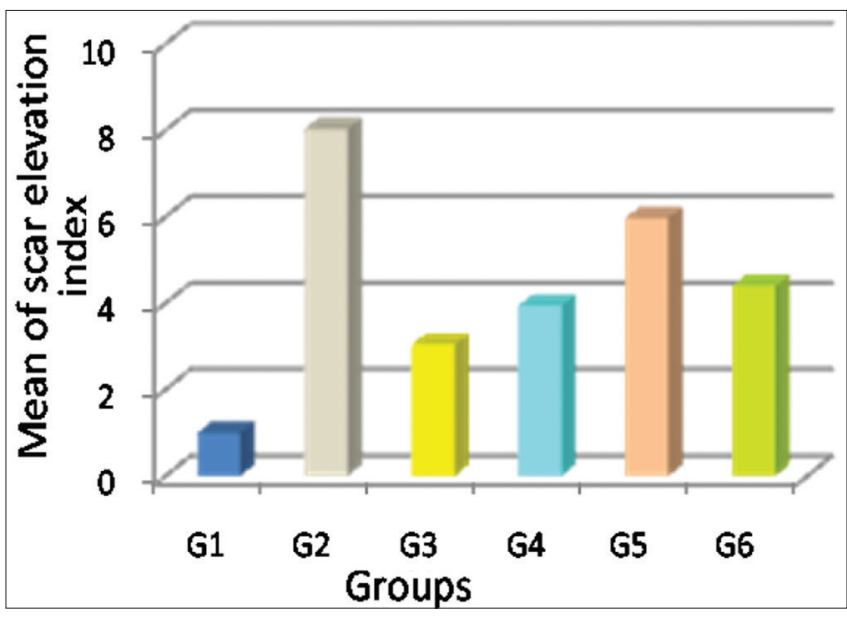

Figure 7: Mean of scar elevation index in control and study group. (G1) healthy control, (G2) induced hypertrophic scar, (G3) TA steroid, (G4) crude FO, (G5) phytosterol $0.2 \%$, (G6) phytosterol $0.4 \%$

The present work demonstrated characteristic histological changes in the untreated hypertrophic scar, radically increase in fibroblast count, inflammation degree, and index of the scar. Regarding inflammation, the current study showed that triamcinolone acetonide significantly

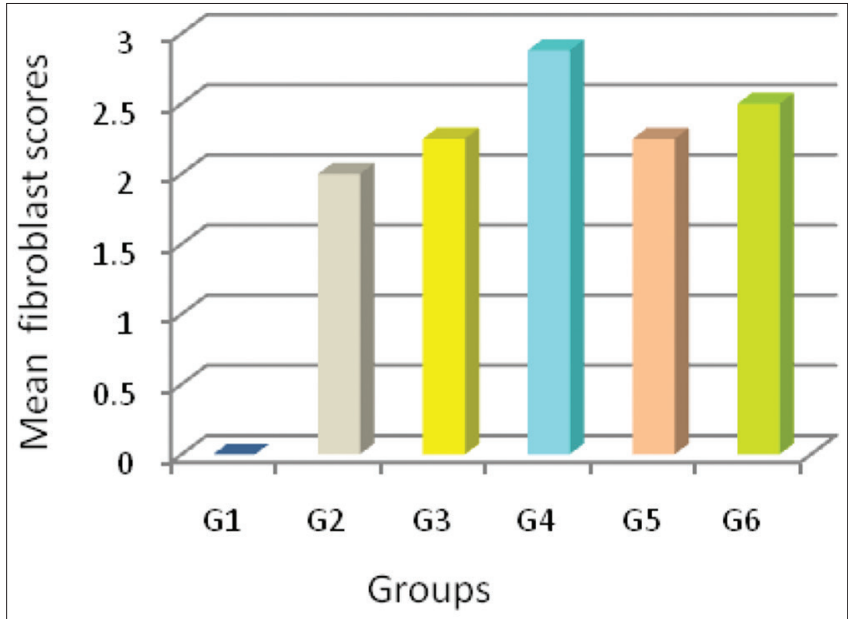

Figure 8: Mean of fibroblast count of control and study group (G1) healthy control, (G2) induced hypertrophic scar, (G3) triamcinolone acetonide steroid, (G4) crude FO, (G5) phytosterol 0.2\%, (G6) phytosterol 0.4\%

reduced the infiltration of inflammatory cell induced by punch biopsy in rabbit ear model.

Pessoa et al. [54] described the anti-inflammation activity of triamcinolone acetonide after 14 days' treatment in the wound of rats' model and registered nearly same observation of our results. In part of herb, aerial part of crude $F$. officinalis possesses marked anti-inflammatory effect while phytosterol fraction of $F$. officinalis showed dose depended on anti-inflammation with higher significant decrease observed at the dose of $0.4 \%$ then $0.2 \%$ of a topical gel. This finding agrees with Rizvi et al. [52] that documented the anti-inflammatory activity and scavenging effect of leaves of F. parviflora through inhibition of various cytokines in rats. Phytosterols of $F$. officinalis $L$. have anti-inflammatory action [21], anti-inflammatory of $F$. officinalis L. can also relate to various phytochemicals such as isoquinoline alkaloids (fumaric acid), phenolic compounds, and flavonoid [55]. Crude F. officinalis L. is comparable to TAC as both have been shown the most anti-inflammation effect in this study.

On the other hand, results of fibroblast count showing the following, TAC exhibited an insignificant change in the presence and organization of fibroblast in the experimentally induced hypertrophic scar, this finding agrees with the observation of Çaliskan et al. in 2016 [56]. Crude F. officinalis $L$. produced a significant reduction of fibroblast count while phytosterol fraction of $0.2 \%$ and $0.4 \%$ showed insignificant alteration in fibroblast count. The effect of phytosterol on decrease proliferation of fibroblast is dose depended as $0.4 \%$ topical gel produced more reduction in this finding.

Which is agree with Capistrano et al. in 2015 [57] that identified alkaloid (protopine and Sanguinarine) of Chelidonium majus L. (Papaveraceae) and detected the significant cytotoxic activity of this alkaloid against both in vitro human pancreatic cell line and murine of same cell line at a dose of $1.2 \mathrm{mg}$ after IP injection for 3 days?

SEI is obtained with the measurement of highest vertical height from perichondrium to epidermal surface in scar area and normal tissue around the scar. TAC (standard drug) was shown a significant decrease in the measurement of SEI that agrees with Çaliskan et al. [56]. Regarding herb, crude F. officinalis L. and phytosterol extract of $(0.2 \%$ and $0.4 \%)$ established a significant reduction of index of scar with extreme reduction were observed in crude F. officinalis L. and high dose of phytosterol this results is disagreeing with Saulis et al. [29] that detected an insignificant decrease in scar index after 4 weeks' treatment with onion extract in rabbits ear model. 


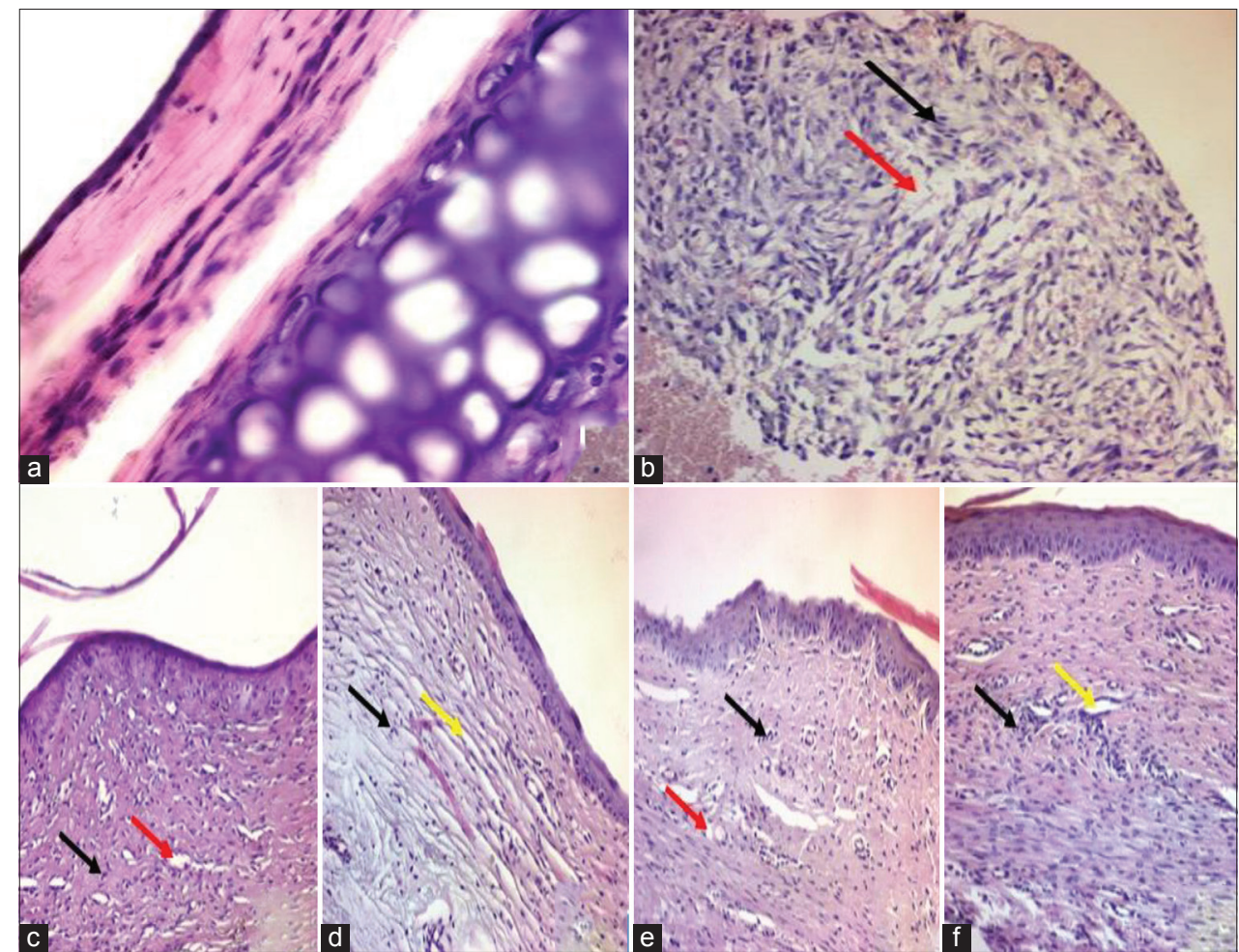

Figure 9: Some of the histological sections from all groups stained with $\mathrm{H}$ and $\mathrm{E}$ stain and examined for inflammation (black arrow),

fibroblast count and arrangement (yellow arrow organized fibroblast), (red arrow disorganized fibroblast) $(\times 20)$. (a) Normal dermal tissue characterized with the absence of inflammatory cell and fibroblast), (b) induced hypertrophic scar tissue represents severe inflammation and high number of polymorph nuclear cells, also dermis cellularity increases, fibroblasts were increased and arranged in a disorganized manner. (c) Hypertrophic scar of $0.1 \%$ triamcinolone acetonide group, (d) hypertrophic scar of $3 \%$ FO grow, (e) hypertrophic of $0.2 \%$ of phytosterol group, (f) hypertrophic $0.4 \%$ of phytosterol of FO group

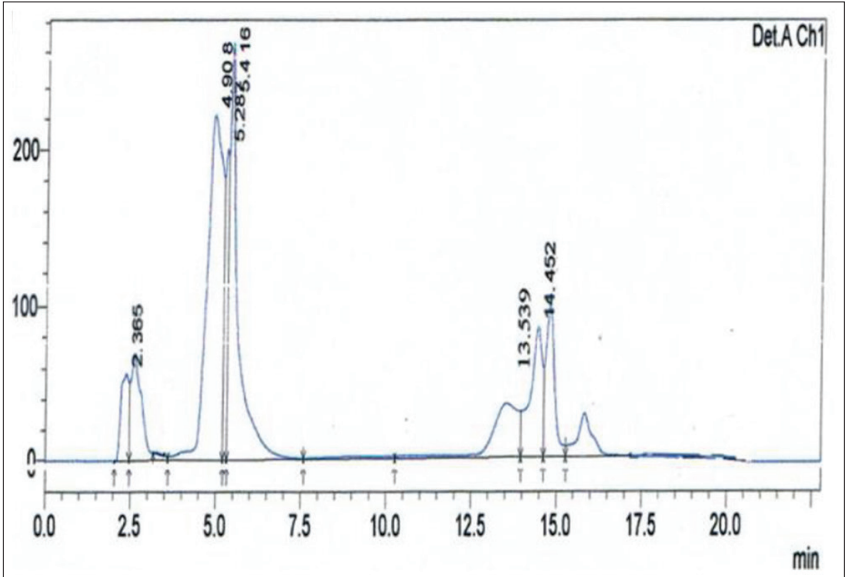

Figure 10: High-performance liquid chromatography chromatogram of sterols fraction

Two groups were the diminishing thickness of hypertrophic scar due to net beneficial effect in the process of wound healing includes TAC and crude $F$ officinlis L.

\section{CONCLUSION}

The crude extract of $F$. officinalis seems to be more effective in reducing scar in compared to phytosterol extract of $F$. officinalis and comparable to TAC.

\section{ACKNOWLEDGMENT}

The authors are grateful to the College of Medicine, AL-Nahrain University, for giving the opportunity and facilities to achieve this work.

\section{AUTHOR'S CONTRIBUTIONS}

The corresponding author has done all the work, interpreted the data, and written the manuscript.

\section{CONFLICTS OF INTEREST}

All authors declare that they have no conflicts of interest.

\section{REFERENCES}

1. Lee HJ, Jang YJ. Recent understandings of biology, prophylaxis and treatment strategies for hypertrophic scars and keloids. Int J Mol Sci 2018;19:E711.

2. Gauglitz GG, Korting HC, Pavicic T, Ruzicka T, Jeschke MG. Hypertrophic scarring and keloids: Pathomechanisms and current and emerging treatment strategies. Mol Med 2011;17:113-25.

3. Wolfram D, Tzankov A, Pülzl P, Piza-Katzer H. Hypertrophic scars and keloids-a review of their pathophysiology, risk factors, and therapeutic management. Dermatol Surg 2009;35:171-81.

4. O'Leary R, Wood EJ, Guillou PJ. Pathological scarring: Strategic interventions. Eur J Surg 2002;168:523-34.

5. Krakowski AC, Totri CR, Donelan MB, Shumaker PR. Scar management in the pediatric and adolescent populations. Pediatrics 2016;137:e20142065.

6. Bombaro KM, Engrav LH, Carrougher GJ, Wiechman SA, Faucher L, Costa BA, et al. What is the prevalence of hypertrophic scarring following burns? Burns 2003;29:299-302.

7. Ren HT, Hu H, Li Y, Jiang HF, Hu XL, Han CM, et al. Endostatin inhibits hypertrophic scarring in a rabbit ear model. J Zhejiang Univ Sci B 2013;14:224-30.

8. Niessen FB, Spauwen PH, Schalkwijk J, Kon M. On the nature of hypertrophic scars and keloids: A review. Plast Reconstr Surg 1999; $104: 1435-58$

9. Dakhil AS. Association of serum concentrations of proinflammatory cytokines and hematological parameters in rheumatoid arthritis patients. J Pharm Sci Res 2017;9:1966-74. 
10. Andrews JP, Marttala J, Macarak E, Rosenbloom J, Uitto J. Keloids: The paradigm of skin fibrosis-pathomechanisms and treatment. Matrix Biol 2016;51:37-46.

11. Klass BR, Grobbelaar AO, Rolfe KJ. Transforming growth factor beta1 signalling, wound healing and repair: A multifunctional cytokine with clinical implications for wound repair, a delicate balance. Postgrad Med J 2009;85:9-14.

12. Xie JL, Qi SH, Pan S, Xu YB, Li TZ, Liu XS, et al. Expression of smad protein by normal skin fibroblasts and hypertrophic scar fibroblasts in response to transforming growth factor beta1. Dermatol Surg 2008;34:1216-24.

13. Wang R, Ghahary A, Shen Q, Scott PG, Roy K, Tredget EE, et al. Hypertrophic scar tissues and fibroblasts produce more transforming growth factor-beta1 mRNA and protein than normal skin and cells. Wound Repair Regen 2000;8:128-37.

14. Mezher MN, Dakhil AS, Jawad DH. Role of epstein-barr virus (EBV) in human females with breast cancer. J Pharm Sci Res 2017:9:1173-7.

15. Thomas F. PDR for Herbal Medicines. Montvale, New Jersey: Medical Economics Company; 2000. p. 322.

16. Sturm S, Strasser EM, Stuppner H. Quantification of Fumaria officinalis isoquinoline alkaloids by nonaqueous capillary electrophoresis-electrospray ion trap mass spectrometry. J Chromatogr A 2006;1112:331-8.

17. Dermaderosian A, Beutler JA. The Review of Natural Products. $4^{\text {th }}$ ed. Baltimore, MD: Lippincott Williams and Wilkins, Wolters Kluwer Health Inc.; 2005. p. 458-60.

18. Molokhova LG, Suslina ML, Datskovskii SB, Figurkin BA. Anti-inflammatory effect of fumitory alkaloids. Tr Permsk God Med Inst 1973;118:26-8.

19. Dakhil AS. Biosynthesis of silver nanoparticle (AgNPs) using Lactobacillus and their effects on oxidative stress biomarkers in rats. J King Saud Univ Sci 2017;29:462-7.

20. Grattan BJ Jr. Plant sterols as anticancer nutrients: Evidence for their role in breast cancer. Nutrients 2013;5:359-87.

21. Awad AB, Williams H, Fink CS. Phytosterols reduce in vitro metastatic ability of MDA-MB-231 human breast cancer cells. Nutr Cancer 2001;40:157-64

22. Harborne JB. Phytochemical Methods, a Guide to Modern Techniques of Plant Analysis. $1^{\text {st }}$ ed. London, New York: Chapman and Hall; 1979. p. 278.

23. Dakhil AS, Al-Hajjiah NN, Shlash RF. Identification of factor viii gene mutations in patients with haemophilia A. Int J Res Pharm Sci 2018;9:274-28.

24. Singh MP, Nagori BP, Shaw NR, Tiwari M, Jhanwar B. Formulation development and evaluation of topical gel formulations using different gelling agents and its comparison with marketed gel formulation. Int J Pharm Erudition 2013;3:1-10.

25. Attia MA, El-Gibaly I, Shaltout SE, Fetih GN. Transbuccal permeation, anti-inflammatory activity and clinical efficacy of piroxicam formulated in different gels. Int J Pharm 2004;276:11-28.

26. Yagmur C, Guneren E, Kefeli M, Ogawa R. The effect of surgical denervation on prevention of excessive dermal scarring: A study on rabbit ear hypertrophic scar model. J Plast Reconstr Aesthet Surg 2011;64:1359-65.

27. Weiss AT, Delcour NM, Meyer A, Klopfleisch R. Efficient and cost-effective extraction of genomic DNA from formalin-fixed and paraffin-embedded tissues. Vet Pathol 2011;48:834-8.

28. Anderson G, Gordon KC. Tissue processing, microtomy, andparaffin sections. In: Bancroft D, Stevens A, editrors. Theory and Practice of Histological Techniques. New York: Churchill Livingstone; 1996. p. 47-67.

29. Saulis AS, Mogford JH, Mustoe TA. Effect of mederma on hypertrophic scarring in the rabbit ear model. Plast Reconstr Surg 2002;110:177-83.

30. Longo RE, Sao Dimas J. Effects of Chamomilla recutita (L) on oral wound healing in rats. Cir Bucal 2002;16:e716-21.

31. Gál P, Vasilenko T, Kostelníková M, Jakubco J, Kovác I, Sabol F, et al. Open wound healing in vivo: Monitoring binding and presence of adhesion/growth-regulatory galectins in rat skin during the course of complete re-epithelialization. Acta Histochem Cytochem 2011;44:191-9.

32. Prignano F, Campolmi P, Bonan P, Ricceri F, Cannarozzo G, Troiano M, et al. Fractional CO2 laser: A novel therapeutic device upon photobiomodulation of tissue remodeling and cytokine pathway of tissue repair. Dermatol Ther 2009;22 Suppl 1:S8-15.

33. Daniel WW. 7.10, determining sample size to control Type II errors. In: Biostatistics a Foundation for Analysis in the Health Sciences. $9^{\text {th }}$ ed. Ch. 7. Hoboken, New Jersey: Wiley; 2009. p. 278.

34. Mehta M, Branford OA, Rolfe KJ. The evidence for natural therapeutics as potential anti-scarring agents in burn-related scarring. Burns Trauma 2016;4:15.
35. Penn JW, Grobbelaar AO, Rolfe KJ. The role of the TGF- $\beta$ family in wound healing, burns and scarring: A review. Int J Burns Trauma 2012;2:18-28.

36. Ko JH, Kim PS, Zhao Y, Hong SJ, Mustoe TA. HMG-coA reductase inhibitors (statins) reduce hypertrophic scar formation in a rabbit ear wounding model. Plast Reconstr Surg 2012;129:252e-61e.

37. Tang M, Wang W, Cheng L, Jin R, Zhang L, Bian W, et al. The inhibitory effects of 20(R)-ginsenoside rg3 on the proliferation, angiogenesis, and collagen synthesis of hypertrophic scar derived fibroblasts in vitro. Iran J Basic Med Sci 2018;21:309-17.

38. Lu L, Saulis AS, Liu WR, Roy NK, Chao JD, Ledbetter S, et al. The temporal effects of anti-TGF-beta1, 2, and 3 monoclonal antibody on wound healing and hypertrophic scar formation. J Am Coll Surg 2005;201:391-7.

39. Wick G, Grundtman C, Mayerl C, Wimpissinger TF, Feichtinger J, Zelger B, et al. The immunology of fibrosis. Annu Rev Immunol 2013;31:107-35.

40. Manna MJ, Abu-Raghif A, Abbood MS. Effect of captopril on inflammatory biomarkers, oxidative stress parameters and histological outcome in experimental induced colitis. J Pharm Sci Res 2017;9:1629-36.

41. Ide M, Jinnin M, Tomizawa Y, Wang Z, Kajihara I, Fukushima S, et al. Transforming growth factor $\beta$-inhibitor repsox down regulates collagen expression of scleroderma dermal fibroblasts and prevents bleomycin-induced mice skin fibrosis. Exp Dermatol 2017;26:1139-43.

42. Klingberg F, Hinz B, White ES. The myofibroblast matrix: Implications for tissue repair and fibrosis. J Pathol 2013;229:298-309.

43. Kim SY, Nam SM, Park ES, Kim YB. Differences in hypertrophic scar fibroblasts according to scar severity: Expression of transforming growth factor $\beta 1$ at the mRNA and protein levels. Arch Aesthetic Plast Surg 2015;21:116-20.

44. Sari E, Bakar B, Dincel GC, Budak Yildiran FA. Effects of DMSO on a rabbit ear hypertrophic scar model: A controlled randomized experimental study. J Plast Reconstr Aesthet Surg 2017;70:509-17.

45. Jurjus A, Atiyeh BS, Abdallah IM, Jurjus RA, Hayek SN, Jaoude MA, et al. Pharmacological modulation of wound healing in experimental burns. Burns 2007;33:892-907.

46. Roa Engel CA, Straathof AJ, Zijlmans TW, van Gulik WM, van der Wielen LA. Fumaric acid production by fermentation. Appl Microbiol Biotechnol 2008;78:379-89.

47. Ivanov I, Vrancheva R, Marchev A, Petkova NT, Aneva IY, Denev PP, et al. Antioxidant activities and phenolic compounds in Bulgarian fumaria species. Int J Curr Microbiol Appl Sci 2014;3:296-306.

48. Al-Hajjiah NN, Almkhadree MA. The effect of maternal anemia on the anthropometric measurements in full-term neonates. Asian J Pharm Clin Res 2018;11:3680-1.

49. Al-Hajjiah NN, Al-Shamsi MM, Al-Shami MM. The rate of parental refusal lumbar puncture in the maternity and children teaching hospital in Diwaniyah, Iraq. J Pharm Sci Res 2018;10:2680-1.

50. Oliveira GV, Hawkins HK, Chinkes D, Burke A, Tavares AL, Ramos-e-Silva M, et al. Hypertrophic versus non hypertrophic scars compared by immunohistochemistry and laser confocal microscopy: Type I and III collagens. Int Wound J 2009;6:445-52.

51. Uzun H, Bitik O, Hekimoğlu R, Atilla P, Kayikçioğlu AU. Angiotensin-converting enzyme inhibitor enalapril reduces formation of hypertrophic scars in a rabbit ear wounding model. Plast Reconstr Surg 2013;132:361e-71e.

52. Rizvi W, Fayazuddin M, Singh O, Syed SN, Moin S, Akhtar K, et al. Anti-inflammatory effect of Fumaria parviflora leaves based on TNF- $\alpha$, IL-1, IL-6 and antioxidant potential. Avicenna J Phytomed 2017; 7:37-45

53. Pandey G, Kumar GR, Gupta SS, Ojha SK, Rao CV. Wound repair and anti-inflammatory potential of Fumaria indica in excision wound-induced rats. Br J Pharm Res 2014;4:257-66.

54. Pessoa ES, Melhado RM, Theodoro LH, Garcia VG. A histologic assessment of the influence of low-intensity laser therapy on wound healing in steroid-treated animals. Photomed Laser Surg 2004:22:199-204

55. Shakya A, Chatterjee SS, Kumar V. Holistic psychopharmacology of Fumaria indica (Fumitory). Chin Med 2012;3:182-99.

56. Calıskan E, Gamsızkan M, Açıkgöz G, Durmus M, Toklu S, Doğrul A, et al. Intralesional treatments for hypertrophic scars: Comparison among corticosteroid, 5-fluorouracil and botulinum toxin in rabbit ear hypertrophic scar model. Eur Rev Med Pharmacol Sci 2016;20:1603-8.

57. Capistrano IR, Wouters A, Lardon F, Gravekamp C, Apers S, Pieters L, et al. In vitro and in vivo investigations on the antitumour activity of Chelidonium majus. Phytomedicine 2015;22:1279-87. 